\title{
TOXIC EFFECTS OF PARAQUAT DICHLORIDE LEACHATE ON TESTES AND SPERM PARAMETERS OF MALE WISTAR RATS
}

\author{
Akintunde O.Wasiu *, Abdulrahman Abdulfatai.
}

Department of Anatomy, Faculty of Basic Medical Sciences, College of Health Sciences Ladoke Akintola University of Technology, Ogbomoso, Nigeria.

\section{ABSTRACT}

Herbicide(s) commonly known as weedkillers, are chemical substances used to control unwanted plants. Paraquat (PQ) (1, 1-dimethyl 4, 4- bipyridillium dichloride) is the active component of the herbicide (Parae Force) used in this study.

This study was performed on 25 male Wistar rats that were divided into 5 groups (A, B, C, D and E), Group A served as the control group that received only distilled water, Group B, C, D \& E served as the treated groups that received $25 \%, 50 \%, 75 \%$, \& 100\% leachate of Paraquat dichloride concentration respectively for 8 weeks.

This study investigated the effect of paraquat dichloride on the testes, sperm characteristics and body weight in adult male Wistar rats. Histological analysis of the testes as well as semen analysis was carried out.

Histomorphometry study of the testes showed deformed seminiferous tubules with irregular shape and spermatogenesis was arrested. Interstitial space was comparatively loose and disrupted Leydig cells are also visible. Seminiferous tubules also exhibiting degenerated basement membrane along with degenerated interstitial cells, degenerated spermatogonia and damaged Sertoli cells. Consequently, the sperm count from the Paraquat dichloride exposed semen revealed significant decreased results, the sperm morphology and sperm progressivity were also affected negatively.

In conclusion, the present study indicates that Paraquat dichloride demonstrated toxic effects on male reproductive parameters.

KEY WORDS: Paraquat dichloride, Testis, Sperm parameter, Rat.

Address for Correspondence: Dr. Akintunde O.Wasiu, Department of Anatomy, Faculty of Basic Medical Sciences, College of Health Sciences Ladoke Akintola University of Technology, Ogbomoso, Nigeria. Mobile+2348033977181, E-Mail: owakintunde@lautech.edu.ng

Access this Article online Quick Response code

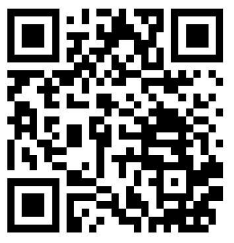

DOI: $10.16965 /$ ijar.2018.457

Journal Information

International Journal of Anatomy and Research

ICV for 2016
90.30
ISSN (E) 2321-4287 | ISSN (P) 2321-8967 https://www.ijmhr.org/ijar.htm DOI-Prefix: https://dx.doi.org/10.16965/ijar

\section{Article Information}

Received: 30 Dec 2018

Peer Review: 01 Jan 2019

Revised: None
Accepted: 12 Feb 2019

Published (O): 05 Mar 2019

Published (P): 05 Mar 2019

\section{INTRODUCTION}

Paraquat is consumed and produced very much in the world because it has unique characteristics and is a very powerful herbicide $[1,3,4]$.

Paraquat ( $N, N 2$-dimethyl-4,42 -bipyridiniumdichloride) is the organic compound with the chemical formula $\left[\left(\mathrm{C}_{6} \mathrm{H}_{7} \mathrm{~N}\right)_{2}\right] \mathrm{Cl}_{2}$. This salt is one of the most widely used herbicides. It is quick-acting and non-selective, killing green plant tissue on contact. It is also toxic to human beings and animals [1]. The name is derived from the para positions of the quaternary nitrogen. Quantities are sometimes expressed by cation mass alone (paraquat cation, paraquat ion); other salts (with other anions besides chloride) exist. Household formulations are also available for clearing paths and flower or vegetable beds $[2,3,4]$. 
It was first synthesized in 1882, although the herbicidal properties were not recognized until 1955 [2]. It was first manufactured and sold by $\mathrm{ICl}$ in early 1962, and is today among the most commonly used herbicides. Paraquat is non- explosive and non-flammable in aqueous formulations. It is corrosive to metals and imcompatible with alkylarylsulfonate wetting agents. It is stable in acid or neutral solutions but is readily hydrolysed by alkali. Paraquat readily undergoes a single-electron reduction to the cation radical [5].

Animal studies have shown paraquat to be excreted rapidly by the kidneys. 80 to $90 \%$ is excreted within 6 hours and almost $100 \%$ within 24 hours, in the absence of paraquat induced renal disease. However, paraquat may cause renal tubular necrosis which can prolong excretion up to 10 to 20 days. Excretion in humans is thought to be similar and to involve active renal secretion as well as glomerular filtration [6].

Rat and dog studies $[7,8]$ revealed that rapid but incomplete absorption of paraquat occurred from the gastrointestinal tract somewhere beyond the stomach. Probably less than $5 \%$ is absorbed. Information on paraquat absorption in man is sparse but is assumed to be the same; however there is limited evidence to support this [5]. Information on absorption from other routes is even more scanty [9]. The absorbed Paraquat is distributed via the bloodstream to practically all organs and tissues of the body. Paraquat is not metabolized but is reduced to an unstable free radical which is then re-oxidized to reform the cation and produce a superoxide anion.

The risk is largely dependent on route of exposure as well as dose. The target organs are: lungs, kidneys, liver and myocardium.

\section{MATERIALS AND METHODS}

Animals: A total of twenty - five healthy, sexually active male Wistar rats weighing between 117 - 145g were randomly divided into five groups, namely control and four treated groups, $(n=5)$. They were housed individually in plastic cages and acclimatized under a 12 hrs light-12 hrs dark photoperiod, relative humidity was approximately $30-40 \%$ and temperature was maintained at $25 \pm 2 \circ \mathrm{C}$. The rats were fed with pelletized feed and water was given ad libitum.
The four treated groups (B, C, D and E) were exposed to leachate from the herbicide (Parae Force) sprayed land. Administration was done orally with the aid of a syringe with attached metal cannula once daily for 8 weeks.

Preparation of the Leachate: $100 \mathrm{ml}$ of herbicide (Parae Force) was poured into 8 litres of water and was sprayed with spray nozzle onto a portion of farm land ( 40 by 80 feet) daily for 2 weeks. This was done during raining season. $1000 \mathrm{ml}$ clean water was added to $10 \mathrm{~kg}$ of sand from the sprayed area and left overnight, the mixture was sieved and the solution (leachate) was diluted into different concentrations and given to the rats (Table 1 ).

Table 1: Preparation and Administration of the leachate.

\begin{tabular}{|c|c|c|c|c|}
\hline $\begin{array}{c}\text { Groups } \\
(\mathrm{n}=5)\end{array}$ & $\begin{array}{c}\text { Concentrations } \\
(\%)\end{array}$ & $\begin{array}{c}\text { Water } \\
(\mathrm{ml})\end{array}$ & $\begin{array}{c}\text { Leachate } \\
(\mathrm{ml})\end{array}$ & $\begin{array}{c}\text { Dose per rat } \\
(\mathrm{ml})\end{array}$ \\
\hline A & 0 & 1000 & 0 & 1.5 \\
\hline B & 25 & 750 & 250 & 1.5 \\
\hline C & 50 & 500 & 500 & 1.5 \\
\hline D & 75 & 250 & 750 & 1.5 \\
\hline E & 100 & 0 & 1000 & 1.5 \\
\hline
\end{tabular}

Sample collection and processing: After treatment, the rats were sacrificed by cervical dislocation and dissected. The testes and epididymis were harvested immediately. The testes were fixed in Bouin's fluid and processed by the method for paraffin embedment and stained with Hematoxylin and Eosin ( $H$ \& E). The slides of testes were evaluated for pathological changes under light microscope.

Semen Analysis: The epididymis was placed in normal saline for evaluation of sperm quality (sperm count, sperm motility and sperm morphology). The concentration of spermatozoa was determined by the haemocytometer method [10] and also evaluated using the improved Neubauer chamber (Deep 1/10 mm, LABART, Germany).

Statistical Analysis: Data collected were analyzed using two-way analysis of variance (ANOVA) followed by Tukey's (HSD) multiple comparison test with the aid of SPSS (V20; USA). Data were presented as means \pm SEM (standard error of mean). $p \leq 0.05$ was considered statistically significant.

\section{RESULTS}

Physical Observation: Generally, the rats in 
Table 2: Body weight change of rats exposed to paraquat dichloride herbicide.

\begin{tabular}{|c|c|c|c|c|c|c|c|c|c|}
\hline Group & Initial Week & Week 1 & Week 2 & Week 3 & Week 4 & Week 5 & Week 6 & Week 7 & Week 8 \\
\hline$A($ Control) $(n=5)$ & $117.5 \pm 1.4$ & $137.5 \pm 6.6$ & $145.0 \pm 12.2$ & $150.0 \pm 11.2$ & $175.0 \pm 11.2$ & $175.0 \pm 11.1$ & $195.0 \pm 9.3$ & $205.0 \pm 9.3$ & $215.0 \pm 12.8$ \\
\hline$B(25 \%)(n=5)$ & $120.0 \pm 2.0^{* *}$ & $147.5 \pm 3.2^{* *}$ & $185.0 \pm 15.0^{* *}$ & $190.0 \pm 1.9^{* *}$ & $225.0 \pm 17.6^{*}$ & $205.0 \pm 14.6^{* *}$ & $224.0 \pm 17.7^{* *}$ & $235.0 \pm 17.0^{* *}$ & $245.0 \pm 9.4^{* *}$ \\
\hline$C(50 \%)(n=5)$ & $126.3 \pm 1.2^{*}$ & $143.8 \pm 3.8$ & $135.0 \pm 6.1^{* *}$ & $130.0 \pm 5.0^{* *}$ & $155.0 \pm 5.00^{* *}$ & $155.0 \pm 5.0^{* *}$ & $160.0 \pm 6.1^{*}$ & $160.0 \pm 10.0^{*}$ & $170.0 \pm 9.4^{*}$ \\
\hline$D(75 \%)(n=5)$ & $137.5 \pm 1.4^{*}$ & $162.5 \pm 4.3^{*}$ & $165.0 \pm 17.0^{* *}$ & $160.0 \pm 17.0^{* *}$ & $195.0 \pm 16.6^{* *}$ & $180.0 \pm 18.4^{* *}$ & $170.0 \pm 14.6^{* *}$ & $175.0 \pm 13.7^{* *}$ & $200.0 \pm 13.7^{* *}$ \\
\hline$E(100 \%)(n=5)$ & $145.0 \pm 0.9^{*}$ & $161.3 \pm 6.8^{*}$ & $170.0 \pm 12.2^{* *}$ & $150.0 \pm 13.7^{* *}$ & $165.0 \pm 10.0^{* *}$ & $165.0 \pm 10.0^{* *}$ & $175.0 \pm 11.2^{* *}$ & $170.0 \pm 9.4^{*}$ & $170.0 \pm 9.4^{*}$ \\
\hline
\end{tabular}

Body weight: Mean \pm SEM (Standard Error of Mean) where * ${ }^{*}$-value $(P \leq 0.05)$ and ${ }^{* *}=P$ value $(P \geq 0.05)$.

both the control and treatment group displayed an increase in weight. After each administration, the rate at which the animals in the treatment group consumed feed and water was reduced. The rate at which the animals in the treatment group excrete also reduced.

From Table 1, it shows that difference in the average mean and standard error of mean (SEM) between the control group and treated groups were not significant while some are significant $(p<0.05)$.

Testicular histopathology: Histoarchitecture of control rat testes exhibits normal morphology of seminiferous epithelium and basement membrane with all successive stages of spermatogenesis, the lumen and interstitial space containing interstitial cells also normal (Figure 1).

Fig. 1: Photomicrographs of testicular sections using $\mathrm{H}$ \& E stain (Mags $x 40$ and $x 100$ ) of the control group, showing normal seminiferous epithelium and basement membrane (BM). The lumen (L) and interstitial space containing interstitial cells (IC).
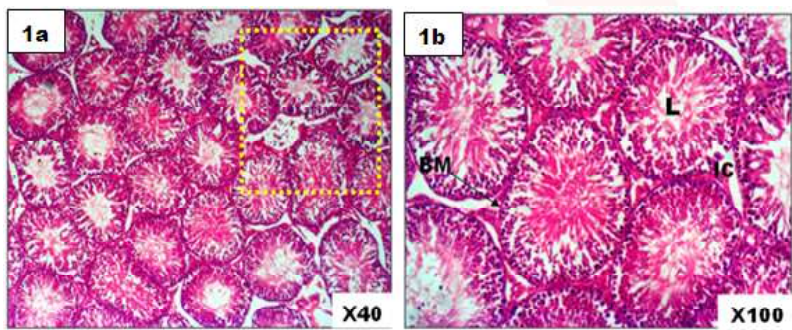

Fig. 2: Photomicrographs of testicular sections using $H$ \& E stain (Mags $x 40$ and $\times 100$ ) of the group B, dosed with $25 \%$ concentration of Paraquat dichloride, showing moderate luminal diameter with some mild observable loss of interstitial cells (IC). Seminiferous tubules are intact (ST) and appear distorted (inset). No severe spermatogenic arrest are observabled.
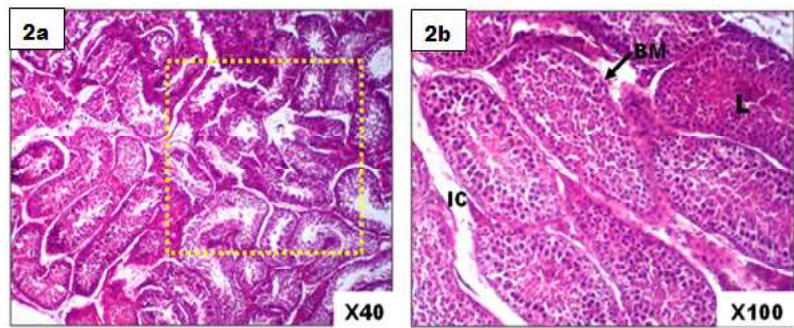

Fig. 3: Photomicrographs of testicular sections using $\mathrm{H}$ \& E stain (Mags $\mathrm{x} 40$ and $\mathrm{x} 100$ ) of the group C, dosed with $50 \%$ concentration of Paraquat dichloride, showing erosion of the luminal content (L), distorted seminiferous tubules (inset), interstitial Leydig with some mild observable loss of interstitial cells (IC). Basement membrane appears broken (BM).
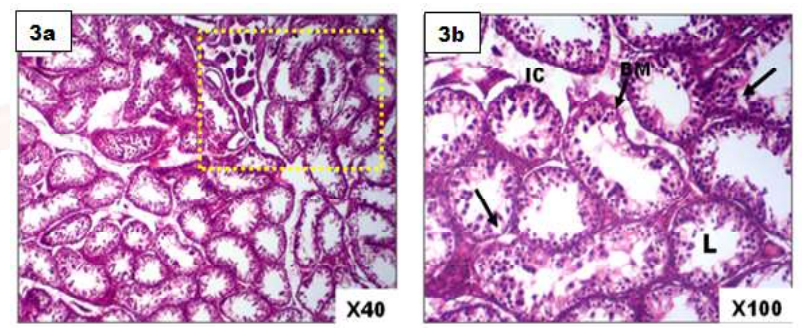

Fig. 4: Photomicrographs of testicular sections using $\mathrm{H}$ \& E stain (Mags $x 40$ and $\times 100$ ) of the group D, dosed with $75 \%$ concentration of Paraquat dichloride, showing interstitial cells with large interstitial spaces, reduced lumenal (L) diameter with observable loss of interstitial cells (IC). Seminiferous tubules appear intact and distorted with detached basement membrane (BM).

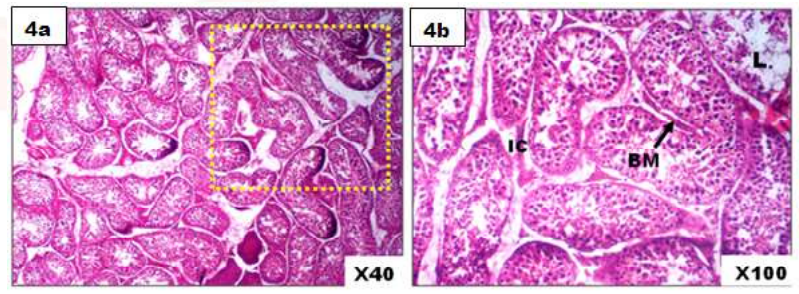

Fig. 5: Photomicrographs of testicular sections using $\mathrm{H}$ \& $E$ stain (Mags $x 40$ and $x 100$ ) of the group $E$, dosed with $100 \%$ concentration of Paraquat dichloride, showing reduction in the luminal diameter $(L)$ and increase in the interstitial space (IS). Seminiferous tubules appear intact and distorted with loss of basal membrane (BM).

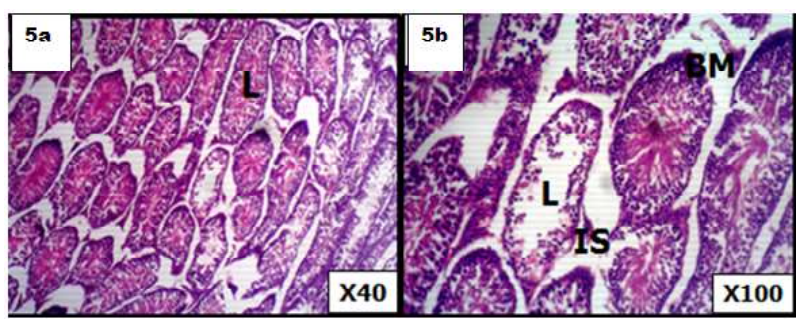

While in treated rats, testicular cell population showed distorted seminiferous tubules with Lumen contain cellular debris. Interstitial space was comparatively loose and disrupted Leydig cells are also visible. Seminiferous tubules 
exhibiting degenerated basement membrane along with degenerated interstitial cells and degenerated spermatogonia and damaged Sertoli cells were also evident (Figure 2-5).

\section{SEMEN ANALYSIS}

Table 3: Showing Mean \pm SEM of Sperm count of the rats exposed to Paraquat dichloride herbicide.

\begin{tabular}{|c|c|}
\hline Groups & Sperm Counts x $10^{6}$ \\
\hline A (Control)(0\%) & $41.07 \pm 1.69$ \\
\hline B (25\%) & $35.73 \pm 2.82$ \\
\hline C (50\%) & $31.87 \pm 0.66^{*}$ \\
\hline D (75\%) & $29.30 \pm 0.64^{*}$ \\
\hline E (100\%) & $24.50 \pm 0.64^{*}$ \\
\hline
\end{tabular}

$* \mathrm{P} \leq 0.05=$ Statistical significantly difference compared with the control rats.

Table 3, shows how Paraquat dichloride was significantly reduced the sperm quantity $(p \leq 0.05)$ of the treated rats at the concentrations of $50 \%,(31.87 \pm 0.66), 75 \%(29.30 \pm 0.64)$ and $100 \%(24.50 \pm 0.64)$, while at $25 \%$ concentration $(35.73 \pm 2.82)$ the rats showed non-significant reduction in quantity of the sperm cells when compared with the control rats $(41.07 \pm 1.69)$.

Table 4: Showing Mean \pm SEM of Sperm Morphology of the rats exposed to Paraquat dichloride herbicide.

\begin{tabular}{|c|c|c|c|c|}
\hline Groups & $\begin{array}{c}\text { Normal } \\
\text { Morphology(\%) }\end{array}$ & $\begin{array}{c}\text { Head Defect } \\
(\%)\end{array}$ & $\begin{array}{c}\text { Mid-piece } \\
\text { Defect (\%) }\end{array}$ & $\begin{array}{c}\text { Tail Defect } \\
(\%)\end{array}$ \\
\hline A(Control)(0\%) & $52.00 \pm 2.89$ & $38.00 \pm 5.00$ & $05.00 \pm 0.58$ & $05.00 \pm 1.16$ \\
\hline B (25\%) & $43.33 \pm 4.41$ & $30.00 \pm 2.88$ & $13.33 \pm 1.76$ & $3.33 \pm 3.881$ \\
\hline C (50\%) & $30.00 \pm 2.89^{*}$ & $40.00 \pm 2.89$ & $20.00 \pm 5.77$ & $10.00 \pm 0.58$ \\
\hline D (75\%) & $26.53 \pm 4.41^{*}$ & $45.58 \pm 4.41$ & $16.56 \pm 1.76$ & $11.33 \pm 2.19$ \\
\hline$E(100 \%)$ & $25.00 \pm 2.89^{*}$ & $50.00 \pm 5.77$ & $12.00 \pm 2.89$ & $13.00 \pm 2.89$ \\
\hline
\end{tabular}

${ }^{*} \mathrm{P} \leq 0.05=$ Statistical significantly difference compared to the control rats.

There was significantly reduction in number of normal sperm morphology at $50 \%$ concentration (30.00 \pm 2.87$), 75 \%$ concentration $(26.53 \pm 4.41)$ and $100 \%$ concentration ( $25.00 \pm 2.89)$. Hence, the abnormal morphologies (head defect, mid-piece defect and tail defect) were increased in number when compared with the control

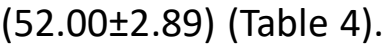

Sperm with rapid progressive motility: are the strongest and swimming fast in a straight line.

Sperm with slow progressive motility: are the weak and swimming in a back and forth manner.

Non-progressive motility: do not move forward despite the fact that they move their tails.
Dead Sperm cells: are immotile and fail to move at all.

Table 5: Showing Mean \pm SEM of Sperm Motility Grading of the rats Exposed to Paraquat dichloride herbicide.

\begin{tabular}{|c|c|c|c|c|}
\hline Groups & $\begin{array}{c}\text { Rapid } \\
\text { Progressive (\%) }\end{array}$ & $\begin{array}{c}\text { Slow } \\
\text { Progressive (\%) }\end{array}$ & $\begin{array}{c}\text { Non } \\
\text { Progressive (\%) }\end{array}$ & $\begin{array}{c}\text { Dead } \\
\text { Sperm Cells (\%) }\end{array}$ \\
\hline$A($ Control)(0\%) & $43.33 \pm 12.02$ & $20.00 \pm 0.58$ & $16.67 \pm 4.410$ & $20.00 \pm 7.64$ \\
\hline$B(25 \%)$ & $40.00 \pm 10.02$ & $20.00 \pm 1.16$ & $20.00 \pm 1.156 *$ & $20.00 \pm 5.77$ \\
\hline$C(50 \%)$ & $40.00 \pm 11.55$ & $20.00 \pm 1.75$ & $15.20 \pm 2.72$ & $25.00 \pm 8.66$ \\
\hline$D(75 \%)$ & $25.00 \pm 8.66$ & $20.00 \pm 1.16$ & $25.00 \pm 2.89$ & $30.00 \pm 5.77$ \\
\hline$E(100 \%)$ & $16.56 \pm 3.38^{*}$ & $16.67 \pm 1.76$ & $16.77 \pm 1.76$ & $50.00 \pm 5.77^{*}$ \\
\hline
\end{tabular}

${ }^{*} \mathrm{P} \leq 0.05=$ Statistical significantly difference compared to the control rats.

Paraquat dichloride affects progressivity of the sperm cells, the number of rapid progressive sperms was low significantly (Pd"0.05) at the concentration of $100 \%(16.56 \pm 3.38)$ and insignificantly $(\mathrm{P}>0.05)$ at the concentrations of $25 \%(40.00 \pm 10.02), 50 \%(40.00 \pm 11.55)$ and $75 \%$ (25.00 \pm 8.66$)$. Meanwhile, the number of dead sperm cells was significantly high at the concentration of $100 \%(50.00 \pm 5.77)$ when compared with the control $(20.00 \pm 7.64)$ (Table 5).

\section{DISCUSSION}

The present study revealed that Paraquat dichloride leads to deformed or irregular Seminiferous Tubules with moderate luminal diameter and mild loss of intertstitial cells in low concentrated dose. Meanwhile, the distortion of Seminiferous Tubules, erupted testicular luminal contents as well as broken of basement membrane were evident when testicular cells were exposed to moderate dose of Paraquat dichloride. In the present study it was also demonstrated that high dose Paraquat dichloride exposure caused increase interstitial space, reduction of the luminal diameter, intact but distorted Seminiferous Tubules with loss of basement membrane at the high dose. Reduction in the diameter may be due to either reduction in the number of cells or their cytoplasm shrinkage. Likewise, It was reported that high dose of Paraquat dichloride resulted in oxidative stress of the testes whereby there is degeneration of cells of testes like Sertoli and leydig cells. Studies showed that Paraquat does not have mutagenic effects and it can weaken the immunity system in bacteria, rat and human, Administration of Paraquat also changes the biochemical parameters of the 
reproductive tract. There is reduction in the weight of the testes and this may be due to decreased number of germ cells and elongated spermatids [11].

Many investigations on the effect of different doses of herbicides, on different organs in different animals have been done. The studies have shown that Paraquat have changes on histopathology in rats and especially in testicle and ovary atrophy [12]. Degeneration of the seminiferous tubules with the formation of small multinucleated giant cells lying free in their lumen was observed in the testes of two of five rats that had been given a single large $200 \mathrm{mg} /$ $\mathrm{kg}$ or few repeated small perioral or peritoneal doses of paraquat [13]. High dose of paraquat have significant effect on spermatocyte, spermatid, leydig cells and parameters of seminiferous tubules because of free radicals in paraquat which have toxic and significant effects on number of spermatogenic cells and parameters of seminiferous tubules. Some histological changes in the testes have been reported in a few paraquat toxicity studies. [14] found multinucleated giant cells in rabbit testicular tubules.

In the present study, the impaired basement membrane leads to low number of sperm cells which possibly resulted into infertility in male. Detached basement membrane is evident. Similarly, It was shown that Paraquat can caused a decrease in the weight of the male reproductive organs in rat such as testes, epididymis, prostate and seminal vesicle and the number of sperms, cell and also decrease in spermatogonia cells [11]. Studies showed that Paraquat does not have mutagenic effects and it can weaken the immunity system in bacteria, rat and human. Paraquat causes decrease in the quantity of sexual cells among Bul/B Syrian rats and also it can wrinkle sexual cells [15].

The reduction in the weight of the testes may be due to decreased number of germ cells and elongated spermatids. 2,4-D reduce spermatogenic potential by reducing their number of sertoli cells, as weight of testes is largely dependent on the mass of differentiated spermatogenic. A decrease in route of spermatogenesis was also observed in rabbits that were given a single toxic dermal dose of paraquat during 24 hours [16].

Although, there are possibility of low sperm cells count to fertilizing eggs if the spermatozoa are viable and are motile in nature but unmoveable and abnormal spermatozoa could not make fertilization possible.

Several secretory product of epididymis may affect sperm which may reduce sperm motility and fertility [17]. Administration of 2, 4-D also changes the biochemical parameters of the reproductive tract. Increased testicular cholesterol concentration may be correlated with its non-utilization by the system leading to a fall in circulating androgen due to anti androgenic activity $[18,19])$. Increased concentration of cholesterol in testes may be the result of its non -utilization leading to the reduction of the production of testosterone, the main hormone involved in the control of fertility of animals including rats [20]. Reduction in glycogen level after the administration of 2, 4-D inhibited the glycogen synthesis which eventually decrease spermatogenesis [21, 22].

As demonstrated in this study, the defected spermatozoa could not fertilise eggs in the ampulla region of the fallopian tube. Meanwhile, the defected spermatozoa are unable to migrate to the point of fertilization because of their affected structural parts which would be very necessary in the progressivity of viable spermatozoa. In the contrary, it was shown that when paraquat was orally administrated to male rats for 60 days, there were multinucleated giant cells in testicular tubules, but there were no significant deviations in the spermatozoa count or motility, no significant changes in histological examination of the testicular tubule cells. On the other hand, the testes of rats, mice, guinea-pig, rabbits and dogs that had been exposed to paraquat aerosols concentrations of up to $0.4 \mathrm{igm} /$ litre for periods of up to three weeks were histologically normal [23]. Also morphologically normal were the testes of a 15 year old boy and two adults [24, 25] fatally poisoned by paraquat as were epididymes, seminal vesicles and prostate.

\section{CONCLUSION}

The results obtained in this study following the administration of paraquat dichloride to adult 
male Wistar rats revealed disruption and distortion of the histo-architecture of the testes. Additionally, it was proved that Paraquat dichloride could change the histological structure of testes and lead to spermatogenesis failure. Moreover, it was found that paraquat dichloride caused some behavioral changes during the administration. With these results, it is cleared that the functions of the testes may be adversely affected as regards male reproduction.

\section{Conflicts of Interests: None}

\section{REFERENCES}

[1]. Lambert CE, Bondy SC. Effects of MPTP, and paraquat on mitochondrial potential and oxidative stress. Life sciences 1989;44(18):1277-84.

[2]. US EPA. Office Of Prevention, Pesticides and Toxic Substances Registraion Eligibility Decision (RED): trifluralin. Washington D.C. April 1996.

[3]. Hamay Atkhah V, Najafiyan M, Farzam M, Kargar H. Effects of the Paraquat Herbicide on Oogenesis and Ovary Structure of Wistar Rat strain. Advances in Environmental Biology. 2004;6(3):1006-12.

[4]. Jafarinejad S, Ghazi-khansari M. Evaluation of the Effects of Captopril on Cytotoxicity of Paraquat in G292 Cell Line. Journal of Isfahan Medical School. 2017;30(196): 12-20.

[5]. Smith LL. Mechanism of paraquat toxicity in lung and its relevance to treatment. Hum Toxicol. 1987;6:31-36.

[6]. Hawksworth GH, Bennett PN, Davies DS. Kinetics of paraquat elimination in the dog. Toxicol, Appl., Pharmacol. 1981;57:139.

[7]. Smith LL, Wright A, Wyatt I, and Rose MS. Effective treatment for paraquat poisoning in rats and its relevance to the treatment of paraquat poisoning in man. Br. Med. J. 1974;4.

[8]. Bennett PN, Davies DS, Hawksworth GH. In vitro absorption studies with paraquat and diquat in the dog. Br J Pharmacol. 1976;58:284.

[9]. Wester RC, Maibach HI, Bucks DA, and Aufrere MB. In vivo percutaneous absorption of paraquat from hand leg and forearm of humans. J Toxicol. Environ. HIth. 1984;14.

[10]. WHO, 1999. Interpretation of semen analysis using WHO 1999 and WHO 2010 reference values: Abnormal become Normal.

[11]. Zain A. The evaluation of the toxic effect of paraquat and its mechanism of action on reproductive system of male rats: Thesis. Universiti Sains Malaysia, Penang 2007. http://eprints. usm.

[12]. Deepananda Ashoka KHM and De Silva WAJ. Mechanism of Paraquat Action shows Interference in Spermatogenesis and Epididymal Maturation of Sperm in Mice. Journal of Biology, 2013;1(3):67-76.
[13]. Clark, D.G, McElligot, T.F and Weston Hurst, E. The Toxicity of paraquat. Brit. J. Industr. Med. 1966;26:126.

[14]. Butler, C and Kleinerman, J. Paraquat in the rabbit, Br. J. ind. Med. 1971;28:67-71.

[15]. Ranjbar A, Mohsenzadeh F, Chehregani A, Khajavi F, Zijoud S, Ghasemi H. Ameliorative effect of Matricaria chamomilla. L on paraquat: Induced oxidative damage in lung rats. Pharmacognosy Research. 2014; 6(3):199.

[16]. Johnson, E., Wayne, S., Cook, K., Nagoshi, R. Phenotypic characterization of no ovaries (nov). A. Dros. Res. Conf. 1992;33: 56.

[17]. Srikanth V, Malini T, Arunakaran J, Govindarajulu P, Balasubramanian K. Effect of ethanol treatment on epididymal secretory product and sperm maturation in albino rats. Pharmacol. 1999;288(2):509519.

[18]. Ohi, H., Shimizu, M., Obata, M., Funabiki, T and Yano, S. Poly[[ $\mu_{3}$-tris(4-phenyl-1,2,3-triazol-1-y)ethyl] amine\}silver(1)] ]hexafluoridophosphate]. Acta Cryst. Section E 2008.

[19]. Narayana K, Prashanthi N, Nayanatara A, Kumar HH, Abhilash K, Bairy KL. 2006. Neonatal methyl parathion exposure affects growth and functions of the male reproductive system in the adult rat. Folia Morphol (Warsz)2006;65(1): 26-33.

[20].Ngoula F, Watcho P, Dongmo MC, Kenfac A, Kamtchouing $P$, Tchoumboue J. Effects of primphosmethyl (an organophosphate insecticide) on the fertility of adult male rats. Afr Health Sci. 2007;7(1): 39.

[21]. Bone W, Jone AR, Morin C, Nieschlag E, Cooper TG. Susceptibility of glycolytic enzyme activities and motility of spermatozoa from rat, mouse and human to inhibition by proven and putative chlorinated antifertility compounds in vitro. J Androl 2001;22(3):464-470.

[22]. Joshi SC, Mathur R, Gilati N. Testicular toxicity of chlorpyrifos (an organophosphate pesticide) in albino rat. Toxicol Ind Health 2007;23: 439-444.

[23]. Gage, J.C. 1968a, Toxicity of Paraquat and diquat aerosols generated by a size selective cyclone: Effect of particle size distribution. Br. J. Ind. Med. 1968a;95:304 - 314.

[24]. Nienhaus $\mathrm{H}$ and Ehrenfeld M. 1971. Pathogenesis of lung disease in paraquat poisoning. Beitr. Path. Anat, 1971;142:244-267.

[25]. Bronkhorst F.B., Van Daal, J.M and Tan, H.D. Fatal outcome of a case of paraquat (Gramoxone) poisoning. Ned. Tijdschr.Geneesk, 1968;112:310-313.

How to cite this article: Akintunde O.Wasiu, Abdulrahman Abdulfatai. TOXIC EFFECTS OF PARAQUAT DICHLORIDE LEACHATE ON TESTES AND SPERM PARAMETERS OF MALE WISTAR RATS. Int J Anat Res 2019;7(1.3):6274-6279. DOI: 10.16965/ijar.2018.457 